\title{
Increased Excitatory Synaptic Transmission Associated with Adult Seizure Vulnerability Induced by Early-Life Inflammation in Mice
}

\author{
${ }^{\circledR}$ Carlos D. Gomez, ${ }^{1}$ Shaona Acharjee, ${ }^{1}$ Megan L. Lewis, ${ }^{1}{ }^{\circledR}$ Justin Read, ${ }^{1}$ and ${ }^{\circledR}$ Quentin J. Pittman ${ }^{1,2}$ \\ ${ }^{1}$ Hotchkiss Brain Institute, Cumming School of Medicine, University of Calgary, Calgary, Alberta T2N 4N1, Canada, and ${ }^{2}$ Snyder Institute for \\ Chronic Disease, Alberta Children's Hospital Research Institute, Department of Physiology and Pharmacology, Cumming School of Medicine, \\ University of Calgary, Calgary, Alberta T2N 4N1, Canada
}

Early-life inflammatory stress increases seizure susceptibility later in life. However, possible sex- and age-specific differences and the associated mechanisms are largely unknown. C57BL/6 mice were bred in house, and female and male pups were injected with lipopolysaccharide (LPS; $100 \mu \mathrm{g} / \mathrm{kg}$, i.p.) or vehicle control (saline solution) at postnatal day 14 (P14). Seizure threshold was assessed in response to pentylenetetrazol $(1 \%$ solution, i.v. $)$ in adolescence $(\sim \mathrm{P} 40)$ and adulthood $(\sim \mathrm{P} 60)$. We found that adult, but not adolescent, mice treated with LPS displayed $\sim 34 \%$ lower seizure threshold compared with controls. Females and males showed similar increased seizure susceptibility, suggesting that altered brain excitability was age dependent, but not sex dependent. Whole-cell recordings revealed no differences in excitatory synaptic activity onto CA1 pyramidal neurons from control or neonatally inflamed adolescent mice of either sex. However, adult mice of both sexes previously exposed to LPS displayed spontaneous EPSC frequency approximately twice that of controls, but amplitude was unchanged. Although these changes were not associated with alterations in dendritic spines or in the NMDA/AMPA receptor ratio, they were linked to an increased glutamate release probability from Schaffer collateral, but not temporoammonic pathway. This glutamate increase was associated with reduced activity of presynaptic $\mathrm{GABA}_{\mathrm{B}}$ receptors and was independent of the endocannabinoid-mediated suppression of excitation. Our new findings demonstrate that early-life inflammation leads to long-term increased hippocampal excitability in adult female and male mice associated with changes in glutamatergic synaptic transmission. These alterations may contribute to enhanced vulnerability of the brain to subsequent pathologic challenges such as epileptic seizures.

Key words: age differences; glutamatergic transmission; hippocampus; lipopolysaccharide; presynaptic $\mathrm{GABA}_{\mathrm{B}}$ receptors; Schaffer collaterals

Significance Statement

Adult physiology has been shown to be affected by early-life inflammation. Our data reveal that early-life inflammation increases excitatory synaptic transmission onto hippocampal CA1 pyramidal neurons in an age-dependent manner through disrupted presynaptic $\mathrm{GABA}_{\mathrm{B}}$ receptor activity on Schaffer collaterals. This hyperexcitability was seen only in adult, and not in adolescent, animals of either sex. The data suggest a maturation process, independent of sex, in the priming action of early-life inflammation and highlight the importance of studying mature brains to reveal cellular changes associated with early-life interventions.

\footnotetext{
Received Oct. 4, 2020; revised Mar. 24, 2021; accepted Mar. 28, 2021.

Author contributions: C.D.G. and Q.J.P. designed research; C.D.G., S.A., M.L.L., and J.R. performed research; C.D.G. and S.A. analyzed data; C.D.G. wrote the paper.

This work was supported by the Natural Sciences and Engineering Research Council of Canada and the Canadian Institutes of Health Research (Q.J.P.). We thank Drs. Mio Tsutsui and Kiarash Riazi for their advice and technical support; and Dr. Adrienne Benediktsson for assistance with the initial Golgi analysis.

The authors declare no competing financial interests.

Correspondence should be addressed to Quentin J. Pittman at pittman@ucalgary.ca.

https://doi.org/10.1523/JNEUROSCI.2667-20.2021

Copyright $\odot 2021$ the authors
}

\section{Introduction}

Preclinical and clinical studies have indicated that exposure to stressful/inflammatory events during the early postnatal period can have an impact on brain physiology and behavior later in life (Hagberg et al., 2012; Danese and Lewis, 2017; Pittman et al., 2019). Along these lines, alterations in neuroimmune functions, behavioral responses, and endocrine changes have been previously described in adult life resulting from a single inflammatory event during a critical period of development caused by the endotoxin lipopolysaccharide (LPS; Rana et al., 2012; Pittman et al., 
2019). Furthermore, early-life exposure to inflammatory stressors, such as LPS, has been shown to prime the brain to subsequent pathologic challenges during adulthood, including responses to physiological and behavioral stressors, and seizure susceptibility (Bilbo et al., 2005; Heida et al., 2005; Galic et al., 2008; Walker et al., 2009; Auvin et al., 2010; Reid et al., 2012; Lewis et al., 2018; Aboubakr et al., 2019; Semple et al., 2020). There is, however, a limited understanding of the mechanisms underlying such vulnerability. Previous studies have given LPS at various times after birth; popular paradigms are the administration of two doses within the first $5 \mathrm{~d}$ of life (most likely equivalent to a third-trimester human) and a single injection at postnatal day 14 (P14), thought to reflect brain development in a human infant $\sim 6$ months of age (Romijn et al., 1991). Because of the rapid developmental changes seen in the rodent brain within the first 3 weeks of life (Dutta and Sengupta, 2016), we have focused our discussion on findings arising from a single low dose $(100 \mu \mathrm{g} / \mathrm{kg})$ of LPS at P14, a time near the end of the stress hyporesponsive period (Schmidt et al., 2003) and when neuronal chloride homeostasis is approximating that of the adult (Ben-Ari et al., 2012).

Early studies have shown that systemic inflammation induced by P14 LPS in rats, although not associated with CNS damage (Lee et al., 2000; Heida et al., 2004, 2005), results in transient activation of microglia and the generation of cytokines, similar to what is seen in adult animals (Galic et al., 2008; Dinel et al., 2014). Most studies of outcomes of early-life exposure to inflammation have been limited to males, although experiments in which both sexes were compared have found some responses to be sex dependent, whereas others are not. For example, there are interesting sex-dependent differences in some, but not all, CNS neurochemical and morphologic responses (Spencer et al., 2006; Kentner et al., 2010; Berkiks et al., 2019b). Depending on the study, there are reported sex-dependent differences in depressive and anxiety-like behaviors (Doenni et al., 2017; Berkiks et al., 2019a), but not in adult social behavior after early-life LPS administration in rats (Doenni et al., 2016). At the molecular level, we previously observed that early-life inflammation induced aberrant intrinsic properties in CA1 pyramidal neurons in only adult male mice (Gomez et al., 2019). Several reports indicate that early-life inflammation increases brain excitability, reflected in part by reduced chemically or electrically induced seizure thresholds in male rats (Heida et al., 2005; Galic et al., 2008; Auvin et al., 2010; Dupuis et al., 2016) or by increased epileptiform-like activity after combined prenatal and postnatal inflammatory stimuli in male mice (Missig et al., 2018). One study in the genetically altered BTBR mouse suggested that early-life inflammation decreased seizure thresholds in both males and females (Lewis et al., 2018). However, sex dependency has not been explored in the C57BL/6 mouse, which is an important omission as we had previously observed specific changes in membrane properties only in adult males of this strain. These differences prompted us to ask whether early LPS administration would alter seizure susceptibility in an age- or sex-dependent manner in C57BL/6 mice, and whether any differences would be correlated with alterations in hippocampal synaptic transmission to find the underlying mechanisms.

\section{Materials and Methods}

Early-life inflammation. All protocols received the approval of the University of Calgary Animal Care Committee, and experiments were conducted in accordance with the Canadian Council on Animal Care regulations. C57BL/6 mice (Charles River Laboratories) were maintained under standard specific pathogen-free conditions at $20-21^{\circ} \mathrm{C}$, on a $12 \mathrm{~h}$ light/dark cycle (light onset at 7:00 A.M.) with food and water available ad libitum. The early-life inflammation paradigm was performed as we previously described (Gomez et al., 2019). Briefly, females were bred, then separated and monitored for the day of birth of the offspring. On P14, male and female offspring in each litter were randomly chosen to receive either pyrogen-free saline (vehicle; $1 \mathrm{ml} / \mathrm{kg}$ ) or LPS (Escherichia coli, serotype 026:B6; $100 \mu \mathrm{g} / \mathrm{kg}$, i.p.), a molecule derived from Gramnegative bacteria that we have earlier shown to induce a transient fever and a mild peripheral and central inflammatory response in the host (Heida et al., 2004; Ellis et al., 2005; Galic et al., 2009). For all subsequent experiments, both female and male offspring were included to reveal any sex-specific interaction, and pups were taken from multiple litters to mitigate possible differences in individual maternal care, and litter and cohort effects. After the early-life treatment, offspring were marked on their ears for later identification, then were returned to their dams, weaned at P21, and housed three to five per cage, assigned by sex and, randomly, by treatment.

Pentylenetetrazol seizure susceptibility assessment. We explored the effect of early-life inflammation on seizure susceptibility in adolescent $(\sim$ P40) and adult $(\sim$ P60) mice neonatally exposed to either LPS or vehicle on P14. With this purpose, the seizure threshold was determined as previously described (Riazi et al., 2004; Lewis et al., 2018). Intravenous infusion of the proconvulsive agent pentylenetetrazol (PTZ; $1 \%$ solution; Sigma-Aldrich) was given to the unrestrained mice through the tail vein at a rate of $1 \mathrm{ml} / \mathrm{min}$ using an infusion pump. The infusion was terminated when a generalized tonic-clonic seizure was observed. The PTZ amount (in milligrams per kilogram) necessary to induce a generalized seizure was then calculated, and was used as a measure of seizure susceptibility.

In vitro hippocampal electrophysiology. To assess whether synaptic properties are altered in later life, adolescent (P35 to P45) and adult (P60 to P70) mice of both sexes, treated with either LPS or vehicle (Veh) on P14 (hereafter labeled as LPS or Veh), were anesthetized with isoflurane and perfused via the heart with cold slicing solution containing the following (in mM): $87 \mathrm{NaCl}, 2.5 \mathrm{KCl}, 25 \mathrm{NaHCO}_{3}, 0.5 \mathrm{CaCl}_{2}, 7 \mathrm{MgCl}_{2}, 1.25$ $\mathrm{NaH}_{2} \mathrm{PO}_{4}, 25$ D-glucose, and 75 sucrose. Both slicing and artificial CSF (aCSF) solutions (described below) were continuously bubbled with a gas mixture of $95 \% \mathrm{O}_{2}$ and $5 \% \mathrm{CO}_{2}$ to maintain a $\mathrm{pH}$ at 7.4. Brains were extracted, and transverse slices $(300 \mu \mathrm{m})$ of the dorsal hippocampus were taken at a $45^{\circ}$ angle from the coronal plane using a vibratome (model VT1200S, Leica), as we described previously (Gomez et al., 2019). We focused on the dorsal hippocampus in this study because of known differences in pyramidal cell properties and function of the hippocampus along its dorsal and ventral extent (Strange et al., 2014). Slices were immediately transferred to a submerged chamber containing warm $\left(32^{\circ} \mathrm{C}\right)$ aCSF composed of the following (in $\mathrm{mm}$ ): $126 \mathrm{NaCl}, 2.5 \mathrm{KCl}, 26$ $\mathrm{NaHCO}_{3}, 2.5 \mathrm{CaCl}_{2}, 1.5 \mathrm{MgCl}_{2}, 1.25 \mathrm{NaH}_{2} \mathrm{PO}_{4}$, and 10 D-glucose, kept for $60 \mathrm{~min}$, and then maintained at room temperature for $30 \mathrm{~min}$ before recording.

To enable recordings, hippocampal slices were perfused with aCSF $\left(32^{\circ} \mathrm{C}\right)$ at a flow rate of $1-2 \mathrm{ml} / \mathrm{min}$, and CA1 pyramidal neurons were identified under differential contrast/infrared illumination by their location in the cell body layer and by their pyramidal shape. Whole-cell patch-clamp recordings were obtained from CA1 neurons using borosilicate glass micropipettes (3-5 M $\Omega$ ) filled with a recording solution containing the following (in $\mathrm{mm}$ ): $108 \mathrm{D}$-gluconic acid, 108 cesium hydroxide, 5 tetraethylammonium-Cl, $2.8 \mathrm{NaCl}$, 20 HEPES, 0.4 EGTA, 4 MgATP, $0.3 \mathrm{NaGTP}, 10$ phosphocreatine $\mathrm{Na}_{2}$, and $1 \mathrm{QX}-314$, with $\mathrm{pH}$ adjusted to 7.2 with $1 \mathrm{CsOH}$ solution and osmolarity adjusted to $\sim 305$ mOsmol. Liquid junction potentials were nullified, and cell capacitance and access resistance (initial value, $<20 \mathrm{M} \Omega$ ) were monitored, with recordings accepted only if either variable did not change by $>20 \%$.

For synaptic experiments, CA1 neurons were voltage clamped at $-70 \mathrm{mV}$ and were allowed to stabilize for at least $5 \mathrm{~min}$. Spontaneous EPSCs (sEPSCs) were isolated by blocking $\mathrm{GABA}_{\mathrm{A}}$ channel-mediated synaptic transmission with picrotoxin $(100 \mu \mathrm{M})$. Evoked synaptic currents were elicited by paired stimulation every $10 \mathrm{~s}$ with an interstimulus interval of $50 \mathrm{~ms}$ using concentric bipolar tungsten electrodes (SNEX- 
100 , Kopf) at $\sim 50 \%$ of maximal stimulation intensity that did not elicit further increases in evoked EPSC (eEPSC) amplitude. One electrode was placed in stratum radiatum (SR) to stimulate the Schaffer collaterals (SCs), and the other was placed in stratum lacunosum moleculare (SLM) to stimulate the temporoammonic (TA) pathway. eEPSC amplitudes were calculated from the baseline to the peak of each evoked response, and the paired-pulse ratio (PPR) was calculated using the amplitude ratio of the evoked pair (peak 2/peak 1). To measure the AMPAR-mediated EPSC, peak responses at $-70 \mathrm{mV}$ were measured, and for NMDAR-mediated EPSC responses, peak responses $50 \mathrm{~ms}$ following stimulation at $+40 \mathrm{mV}$ holding potential were measured. To induce depolarization-induced suppression of excitation (DSE), CA1 neurons were given a depolarizing voltage command to $0 \mathrm{mV}$ for 5 and $10 \mathrm{~s}$. Data were normalized and expressed as a percentage of the baseline values ( -1 to 0 min before the initial DSE step) in each cell. Peak DSE values were obtained by averaging evoked amplitudes every $15 \mathrm{~s}$. To avoid epileptiform activity in CA1, a cut was made at the border of CA1 and CA3. The $\mathrm{GABA}_{\mathrm{B}}$ receptor agonist baclofen $(5 \mu \mathrm{M})$ or the $\mathrm{CB} 1$ receptor antagonist AM251 $(2 \mu \mathrm{M})$ was added to the bath as needed. Signals were amplified and filtered (low pass at $1 \mathrm{kHz}$ ) with a Multiclamp 700B amplifier (Molecular Devices) and digitized at $10 \mathrm{kHz}$ using a data acquisition system (Digidata 1322A, Molecular Devices). Analysis was conducted offline with Clampfit 9.2 (Molecular Devices) and MiniAnalysis (Synaptosoft). Cumulative probability and average values for sEPSC frequency and amplitude from all cells recorded were obtained using MiniAnalysis. All electrophysiological datasets comprised results from animals reported as " $N$ " and number of cells as " $n$," obtained from a minimum of three litters. In addition, data were collected over a period of $>3$ years from multiple cohorts of animals.

Golgi staining. It was important to determine whether dendritic spine counts in the CA1 neurons were similar in the control and LPS groups, considering that our electrophysiological analyses indicated striking differences between properties of adult mice treated with LPS at P14. Therefore, Golgi silver impregnation was done using a commercially available kit (FD Rapid GolgiStain Kit, FD NeuroTechnologies) as we previously described (Acharjee et al., 2018; Gomez et al., 2019). Experimental animals were anesthetized with sodium pentobarbital $(80 \mathrm{mg} / \mathrm{kg}$, i.p.), and the brains were harvested. Coronal sections $(100 \mu \mathrm{m})$ were cut on a vibratome (model VT1000S, Leica), mounted on gelatin-coated slides and developed following the protocol in the FD Rapid GolgiStain Kit. CA1 pyramidal neurons from the dorsal hippocampus were imaged using reflective confocal microscopy (model DM5500 B, Leica) with a $488 \mathrm{~nm}$ laser and a $40 \times$ objective (1.62 numerical aperture). Five neurons were imaged per animal $(N=3-$ 4/group, each from a separate litter). Care was taken to ensure that imaged neurons did not extend processes to the very end part of the sections to avoid dendritic stumps, and that processes of the neurons could be clearly identified. Moreover, neurons chosen were sufficiently distant from their neighbors to minimize the overlap of dendritic trees. Confocal image stacks were imported into ImageJ for analysis. Dendritic spines were counted from the $3 \mathrm{D}$ stacked images using the Cell Counter plugin. For analysis, five CA1 pyramidal neurons were chosen from each animal, and the spines were counted from two dendritic processes from stratum lacunosum moleculare, and two from stratum radiatum of each neuron. Within each dendritic process, spines were counted for a length of $20-60 \mu \mathrm{m}$ from the distal tip, depending on the length of the process. Spine density was calculated by dividing the number of spines by the length of the part of the dendrite from which the spines were counted. Spines with well defined heads and bifurcated spines were identified visually and quantified. All analyses were completed blinded to the experimental/control status of the animal.

Data analysis. All statistical analyses were performed using GraphPad Prism version 8.0. Seizure threshold, synaptic properties, and Golgi staining data were verified for normal distribution, then analyzed using oneway or two-way ANOVA with Tukey's post hoc test, unpaired or paired Student's $t$ test, effect size by Cohen's $d$, and Pearson correlation coefficients as needed. Results are reported as the mean \pm SEM. Statistical significance was set at $p<0.05$ based on the animal number for seizure threshold data and on the number of cells for electrophysiological data.

\section{Results}

Early-life inflammation increases seizure susceptibility in adult mice

To evaluate whether a systemic inflammatory event induced by LPS on P14 influences seizure susceptibility in female and male mice differentially in later life, LPS-pretreated and control adolescent and adult mice of both sexes were injected intravenously with the proconvulsive agent PTZ, and the seizure threshold was then measured (Fig. 1A). All experimental mice developed a generalized tonic-clonic seizure. When comparing effects of earlylife LPS treatment on seizure threshold, significant differences were observed in all female mice (Veh: $92.8 \pm 4.5 \mathrm{mg} / \mathrm{kg}$ PTZ; $N=23$; LPS: $77.7 \pm 5.6 \mathrm{mg} / \mathrm{kg}$ PTZ; $N=21$; unpaired Student's $t$ test: $t_{(42)}=2.1, p=0.04$; Cohen's $d=0.63$; Fig. $1 B$ ) and male mice (Veh: $79.8 \pm 4.3 \mathrm{mg} / \mathrm{kg}$ PTZ; $N=20$; LPS: $66.4 \pm 4.5 \mathrm{mg} / \mathrm{kg}$ PTZ; $N=18 ; t_{(36)}=2.1, p=0.04$; Cohen's $d=0.69$; Fig. $1 D$ ).

Multiple comparisons among groups revealed that the differences were attributed to an $\sim 36 \%$ lower seizure threshold in adult female mice (Veh: $96.9 \pm 5.7 \mathrm{mg} / \mathrm{kg}$ PTZ; $N=13$; LPS: $61.1 \pm 4.1 \mathrm{mg} / \mathrm{kg}$ PTZ; $N=11$; two-way ANOVA: $F_{(1,40)}=12.8$, Tukey's post hoc analysis, $p=0.0006$; Fig. $1 C$ ), but not adolescent female mice (Veh: $87.5 \pm 7.2 \mathrm{mg} / \mathrm{kg}$ PTZ; $N=10$; LPS: $96.1 \pm$ $7.4 \mathrm{mg} / \mathrm{kg}$ PTZ; $N=10 ; p=0.78$; Fig. $1 C$ ) exposed to early-life inflammation compared with controls. Likewise, adult male mice (Veh: $78.8 \pm 5.5 \mathrm{mg} / \mathrm{kg}$ PTZ; $N=11$; LPS: $53.1 \pm 3.9 \mathrm{mg} / \mathrm{kg}$ PTZ; $N=9$; two-way ANOVA: $F_{(1,34)}=4.6$; Tukey's post hoc analysis, $p=0.01$; Fig. $1 E$ ), but not adolescent male mice (Veh: $80.8 \pm 7.2 \mathrm{mg} / \mathrm{kg}$ PTZ; $N=9$; LPS: $79.6 \pm 5.4 \mathrm{mg} / \mathrm{kg}$ PTZ; $N=9$; $p=0.99$; Fig. $1 E$ ) showed similar increases in seizure susceptibility, suggesting age-dependent but not sex-dependent reduced seizure threshold in these mice.

\section{Altered synaptic transmission in adult CA1 pyramidal neurons exposed to early-life inflammation}

Increased seizure susceptibility could be the result of alterations in intrinsic membrane properties of cells or of altered synaptic transmission (Barker-Haliski and White, 2015). As we previously showed that adult males, but not females, displayed altered membrane properties as a result of early-life inflammation (Gomez et al., 2019), it is unlikely that these changes explain the increased seizure susceptibility seen here in both female and male mice. Therefore, we hypothesize that exposure to early-life inflammation leads to changes in synaptic transmission efficacy at glutamatergic synapses onto hippocampal CA1 pyramidal neurons.

With this purpose, whole-cell recordings were obtained and spontaneous EPSCs were examined. Figure $2 A$ shows spontaneous EPSCs for representative control (Veh, dark traces) and early LPS-inflamed (LPS, green traces) CA1 pyramidal neurons from both adolescent and adult female mice. When spontaneous EPSC amplitude was analyzed using two-way ANOVA, no significant differences were found $\left(F_{(1,103)}=0.18, p=0.67\right)$ in early LPS-inflamed CA1 pyramidal neurons of adolescent female mice (Veh: $16.5 \pm 0.8 \mathrm{pA} ; n=28 ; N=5$; LPS: $17.1 \pm 0.8 \mathrm{pA} ; n=26$; $N=6$; Fig. $2 B$ ) and adult female mice (Veh: $17.5 \pm 0.8 \mathrm{pA} ; n=25$; $N=7$; LPS: $17.9 \pm 0.4 \mathrm{pA} ; n=28 ; N=7$; Fig. $2 B$ ) compared with controls. Interestingly, we observed an age $\left(F_{(1,103)}=4.75\right.$, $p=0.03$ ) dependent effect of the early-life LPS treatment on spontaneous EPSC frequency in CA1 pyramidal neurons. Multiple comparisons by Tukey's post hoc analysis revealed that previously inflamed neurons displayed higher spontaneous EPSC frequency, but not amplitude, compared with controls only in adult female mice (Veh: $1.8 \pm 0.3 \mathrm{~Hz} ; n=25 ; N=7$; LPS: 
$3.4 \pm 0.4 \mathrm{~Hz} ; n=28 ; N=7 ; p=0.0005$; Fig. $2 B)$, with no significant changes in adolescent female mice (Veh: $1.4 \pm 0.2 \mathrm{~Hz} ; n=28 ; N=5$; LPS: $1.8 \pm 0.2 \mathrm{~Hz} ; n=26 ; N=6 ; p=0.72$; Fig. $2 B$ ).

We also asked whether early-life inflammation affects the synaptic transmission in male mice. Figure 2C shows spontaneous EPSCs for representative control (Veh, dark traces) and inflamed (LPS, blue traces) CA1 pyramidal neurons from both adolescent and adult male mice. Statistical analysis revealed that, similar to females, no significant differences in spontaneous EPSC amplitude were found (two-way ANOVA: $\left.F_{(1,101)}=0.02 ; p=0.88\right)$ in CA1 pyramidal neurons of neonatally-inflamed adolescent male mice (Veh: $18.0 \pm 0.9 \mathrm{pA} ; n=26 ; N=8$; LPS: $18.9 \pm 0.9 \mathrm{pA} ; n=25 ; N=6$; Fig. $2 D$ ) and adult male mice (Veh: $17.4 \pm 0.8 \mathrm{pA} ; n=28$; $N=5$; LPS: $18.4 \pm 0.8$ pA; $n=26 ; N=7$; Fig. $2 D$ ). When comparing effects of age and early-life inflammation on spontaneous EPSC frequency, however, significant differences were observed $\left(F_{(1,101)}=6.7, p=0.01\right)$. As seen in Figure 2D, left, inflamed CA1 pyramidal neurons of adult males showed higher spontaneous EPSC frequency (Fig. 2D, left: Veh, $1.6 \pm 0.2 \mathrm{~Hz}, n=28$, $N=5 ; \quad$ LPS $, \quad 2.9 \pm 0.3 \mathrm{~Hz}, \quad n=26, \quad N=7$; $p=0.0007$ ), with no changes in adolescent male mice (Fig. 2D, left: Veh, $1.4 \pm 0.2 \mathrm{~Hz}, n=26$, $N=8$; LPS $1.5 \pm 0.2 \mathrm{~Hz}, n=25, N=6 ; p=0.99$ ) compared with controls. These findings suggest an aberrant glutamatergic synaptic transmission only in adult mice exposed to early-life inflammation.

Early-life inflammation selectively increased the probability of glutamate release with no changes in the number of synapses

Factors that could influence the spontaneous EPSC frequency include the number of synapses and the glutamate release probability (Kerchner and Nicoll, 2008; Acharjee et al., 2018). First, we asked whether the higher synaptic frequency found in early LPS-inflamed CA1 pyramidal neurons of adult mice was a result of changes in the number of synapses. Hippocampal CA1 pyramidal neurons receive cortical afferents directly via the TA pathway and indirectly via the SC to their dendrites located in the stratum lacunosum moleculare and stratum radiatum, respectively (Aksoy-Aksel and Manahan-Vaughan, 2013). Using Golgi staining, we thus investigated whether the number of CA1 pyramidal neuron spines located in these two principal regions was affected by early-life inflammation. This method allows a complete staining of the whole neuron, including soma and dendritic trees, hence enabling a detailed analysis of the morphologic features of individual neurons. When spine density was analyzed using two-way ANOVA, no significant differences were found in CA1 pyramidal neurons of adult female mice (SC: Veh, $0.95 \pm 0.05$ spines/ $\mu \mathrm{m}, n=14, N=3$; LPS, $1.03 \pm 0.04, n=14$, $N=3$; TA pathway: Veh, $0.81 \pm 0.05, n=13, N=3$; LPS, $0.93 \pm 0.05, n=14, N=3 ; F_{(1,51)}=0.13, p=0.72$; Fig. $\left.3 A\right)$ and adult male mice (SC: Veh, $0.84 \pm 0.05$ spines $/ \mu \mathrm{m}, n=18, N=4$; LPS,
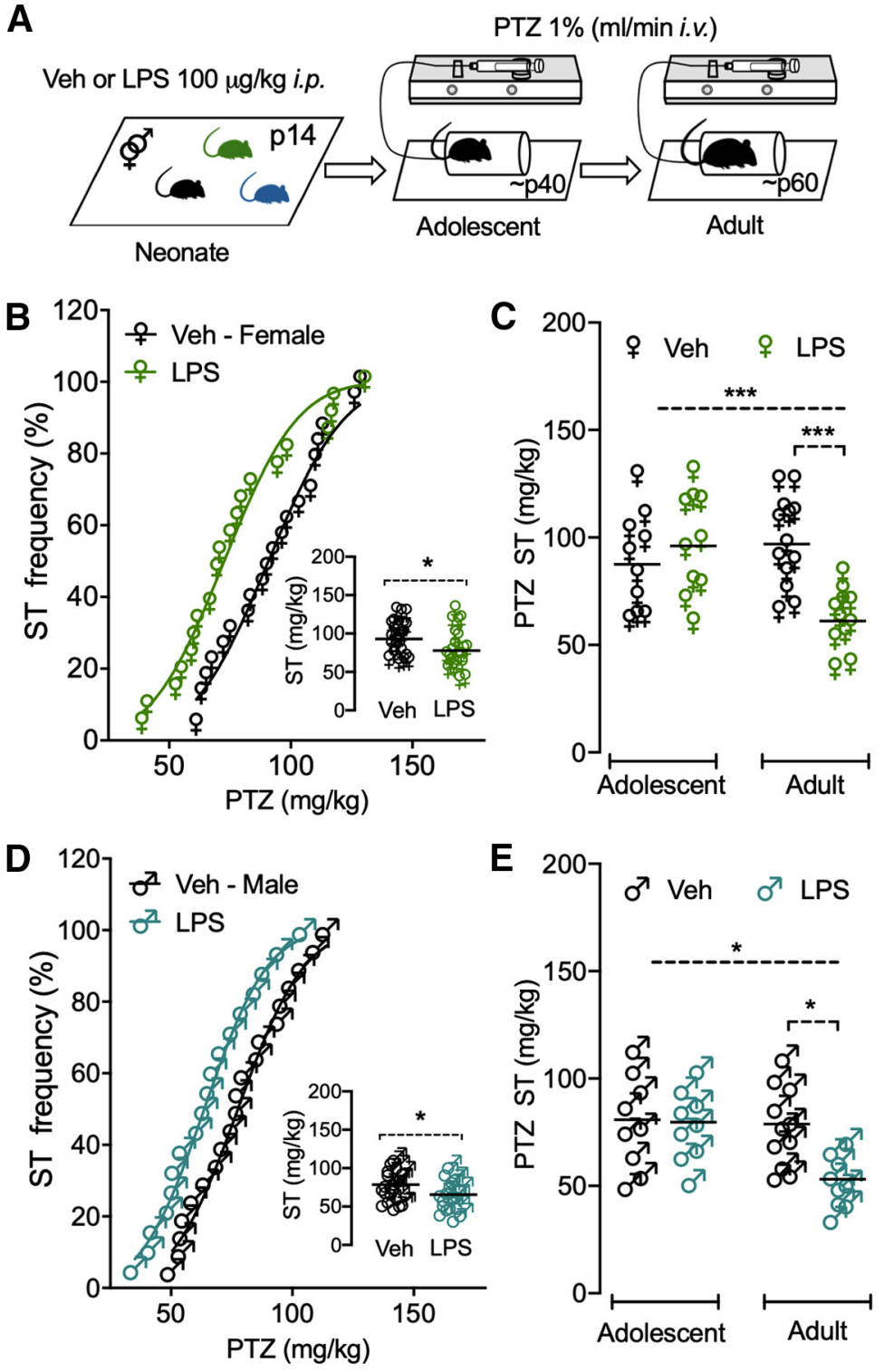

Figure 1. Early-life inflammation reduced seizure threshold to the proconvulsive agent PTZ in adult, but not adowere injected with LPS or Veh at P14, then returned to the home cage. Adolescent ( P P0) and adult ( P60) mice received intravenous infusion of $\mathrm{PTZ}$, which was terminated when a tonic-clonic seizure appeared. $\boldsymbol{B}, \boldsymbol{D}$, Cumulative probability of seizure threshold (ST) frequency in all female $(\boldsymbol{B})$ and male $(\boldsymbol{D})$ mice indicates a left ward shift (reduction) in a dose of PTZ required to elicit a seizure. Insets, Plots depicting amount of PTZ per kilogram of body weight necessary to induce a tonic-clonic seizure in all female $(+)$ and male ( $(\hat{)})$ mice. $\boldsymbol{C}, \boldsymbol{E}$, Summary data on the right show that increased seizure vulnerability (i.e., reduced PTZ dose) was in LPS-treated adult female $(\boldsymbol{C}$ ) and male mice $(\boldsymbol{E})$ compared with controls. No significant differences were observed in seizure threshold in adolescent mice exposed in early life to Veh or LPS. Each symbol represents one animal and the horizontal lines are the mean $(q N=44, \hat{\sigma}$ $N=38)$. $* p<0.05, * * * p<0.001$.

$0.86 \pm 0.04, n=19, N=4$; TA pathway: Veh, $0.68 \pm 0.05, n=18$, $N=4$; LPS, $0.76 \pm 0.06, n=19, N=4 ; F_{(1,70)}=0.33, p=0.56$; Fig. $3 B$ ) exposed to early-life inflammation (green/blue symbols) compared with their respective controls (white symbols). Additionally, considering that changes in spines with well defined heads or bifurcated are associated with spine maturation and synaptic activity, a more in-depth spine morphology analyses was performed. We found, however, that early-life inflammation had no significant effect on either the number of bifurcated spines (female: $F_{(1,51)}=0.04, p=0.85$; male: $F_{(1,70)}=0.05, p=0.82$; Fig. $\left.3 A\right)$, or spines with mature heads (female: $F_{(1,51)}=0.19, p=0.66$; male: 
A
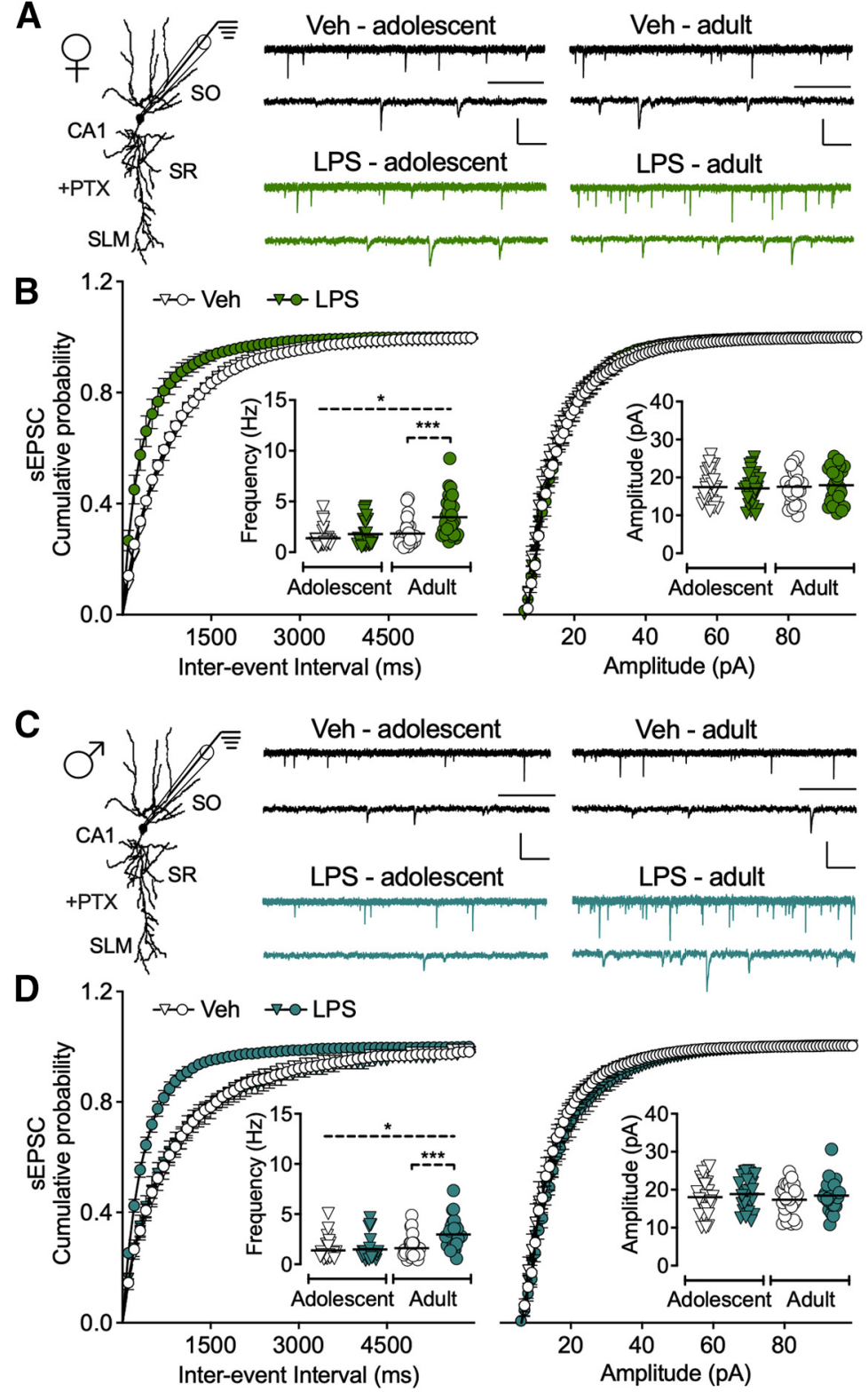

Figure 2. Early-life inflammation increased SEPSC frequency in adult, but not adolescent, mice. $\boldsymbol{A}, \boldsymbol{C}$, Representative traces of spontaneous synaptic activity of CA1 pyramidal cells from female $(\boldsymbol{A})$ and male $(\boldsymbol{C})$ mice previously injected with Veh (dark traces) or LPS (green/blue traces) at P14. Calibration: $20 \mathrm{pA}$; top trace for each color, $1 \mathrm{~s}$; bottom trace, 0.1 s. $\boldsymbol{B}, \boldsymbol{D}$, Cumulative probability distribution of sEPSC frequency (left) and amplitude (right) of pyramidal neurons from female mice $(\boldsymbol{B})$ and male mice $(\boldsymbol{D})$. Insets show frequency and amplitude plotted for individual cells. Summary data display no significant differences in SEPSC amplitude and frequency in adolescent mice early exposed to Veh (white symbols) or LPS (green/blue symbols) at P14. Nevertheless, augmented sEPSC frequency, but not amplitude, was found in LPS-treated adult female and male mice compared with controls. Horizontal lines are the mean ( $n=25-28$ cells, 5-8 mice/group). SO, Stratum oriens; PTX, picrotoxin. $* p<0.05, * * * p<0.001$.

$F_{(1,70)}=0.23, p=0.63$; Fig. $\left.3 B\right)$ of CA1 pyramidal neurons from both sexes compared with controls. Therefore, the absence of changes in spines density, along with no evident changes in the number of bifurcated spines or spines with well defined heads suggests that other mechanisms may account for the differences in spontaneous EPSC frequency that we observed.

A second factor that could influence the spontaneous EPSC frequency is the glutamate release probability, so next we asked whether the higher synaptic frequency found in CA1 pyramidal neurons of adult mice exposed to early-life inflammation was a result of altered presynaptic release. With this purpose, we measured the PPR, a form of short-term plasticity that is a determinant of presynaptic probability of release (Zucker and Regehr, 2002), by stimulating the SC and the TA pathway, two principal pathways that connect with CA1 pyramidal neurons. Figure 4 shows representative traces of evoked EPSC responses to electrical stimulation of presynaptic SC (Fig. $4 A, B$ ) and TA pathway (Fig. 4 $C, D$ ) fibers for control (Fig. $4 A-D$, Veh, dark traces) and inflamed (Fig. $4 A-D$, LPS, green/blue traces) CA1 pyramidal neurons from adult female and male mice. When comparing the effects of early-life LPS treatment on PPR, statistical analysis using two-way ANOVA displayed significant differences among groups in female mice $\left(F_{(1,74)}=\right.$ 4.7, $p=0.03)$ and male mice $\left(F_{(1,88)}=4.5\right.$, $p=0.03$ ). Multiple comparison by Tukey's post hoc analysis revealed that in offspring exposed to early-life LPS inflammation, when SC was stimulated, the PPR was significantly reduced in CA1 pyramidal neurons of adult female mice (Veh: $1.76 \pm 0.05 ; n=18 ; N=7$; LPS: $1.53 \pm 0.04 ; n=22$; $N=7 ; p=0.006$; Fig. $4 A$ ) and male mice (Veh: $1.68 \pm 0.03 ; n=24 ; N=8$; LPS: $1.48 \pm 0.04 ; n=25$; $N=7 ; p=0.004$; Fig. $4 B$ ) compared with controls. On the other hand, when TA pathway was stimulated, the PPR was similar in control and early LPS-inflamed CA1 pyramidal neurons of both adult female mice (Veh: $1.69 \pm 0.05 ; n=19 ; N=6$; LPS: $1.67 \pm 0.04 ; n=19 ; N=6 ; p=0.98$; Fig. $4 C$ ) and adult male mice (Veh: $1.74 \pm 0.05 ; n=22$; $N=5$; LPS: $1.72 \pm 0.04 ; n=21 ; N=5 ; p=0.97$; Fig. $4 D)$. These data suggested increased glutamate release from SC fibers, but not TA fibers. Given that we only observed changes in PPR when SC was stimulated, we focused on that pathway for all additional experiments.

Considering that alterations in spontaneous EPSC frequency could reflect changes in silent synapses (Kerchner and Nicoll, 2008; Acharjee et al., 2018), we examined the AMPA/NMDA ratio, which is a standard approach used to directly estimate changes in the number of silent/unsilent synapses. Statistical analysis showed no significant differences (two-way ANOVA: $F_{(1,58)}=0.44$, $p=0.51)$ in the AMPA/NMDA ratio in CA1 pyramidal neurons of adult female mice (Veh: $5.55 \pm 0.76 ; n=13 ; N=7$; LPS: $6.46 \pm 1.06 ; n=15$; $N=7$; Fig. $5 A$ ) and adult male mice (Veh: $5.81 \pm 0.75 ; n=19 ; N=8$; LPS: $8.0 \pm 1.19 ; n=15$; $N=7$; Fig. $5 B$ ) exposed to early-life inflammation (Fig. 5, green/blue symbols) compared with controls (Fig. 5, white symbols). Together, all these data strongly imply a selective increase of glutamate release from SC fibers with no changes in the numbers of functional synapses.

\section{Preserved endocannabinoid system in adult CA1 pyramidal} neurons exposed to early-life inflammation

The endocannabinoid (eCB) system is a well established modulator of presynaptic glutamate release in nearly all areas of the brain, including the hippocampus (Kreitzer and Regehr, 2001; Maejima et al., 2001). Interestingly, in the amygdala, this system was shown to be affected by early-life inflammation (Zavitsanou 
A

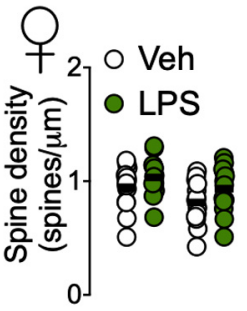

B

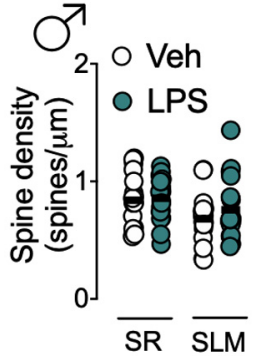

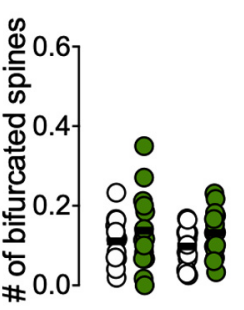

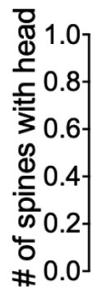

it

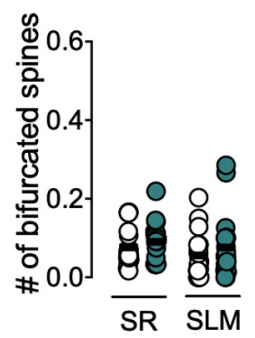

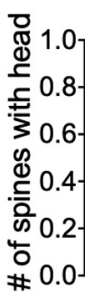

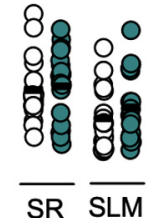

Figure 3. Dendritic spine density of CA1 pyramidal neurons from adult mice is unaltered by early-life inflammation. $\boldsymbol{A}, \boldsymbol{B}$, Scatter graphs show no significant differences in spine density, number of bifurcated spines and number of spines with well defined heads of CA1 pyramidal cells from adult female (green symbols) and male (blue) mice early exposed to LPS compared with controls (white symbols). Each symbol represents one cell, and the horizontal lines are the mean ( $n=13-19$ cells, 3-4 mice/group).

et al., 2013; Doenni et al., 2016). We explored here, the possibility that the eCB pathways somehow could also be altered in adult hippocampus after early-life inflammation, thus causing aberrant presynaptic glutamate release. DSE is an eCB-mediated shortterm synaptic plasticity and a feature that can be used to monitor eCB pathway activities. To achieve a rapid and transient inhibition $(<1 \mathrm{~min})$ through retrograde transmission of eCBs (i.e., DSE) in CA1 pyramidal neurons, long depolarization times (7$10 \mathrm{~s}$ ) are required (Ohno-Shosaku et al., 2002).

As shown in Figure 6, we compared DSE of eEPSCs recorded from control (Veh, black traces) and previously-inflamed (LPS, green/blue traces) CA1 pyramidal neurons from adult female mice $(A)$ and adult male mice $(B)$. Postsynaptic depolarization $(-70$ to $0 \mathrm{mV}$ for $5 \mathrm{~s})$ resulted in an immediate slight, but insignificant depression of eEPSCs in CA1 pyramidal neurons of female mice (DSE: Veh, $5.25 \pm 2.29 \%$ from baseline; one-way ANOVA, $\left.F_{(5,135)}=2.09, p=0.07, n=27, N=6\right)$ and male mice (DSE: Veh, $6.27 \pm 2.45 \%$ from baseline; $F_{(5,84)}=2.13, p=0.07$, $n=13, N=5)$, which recovered within $\sim 30$ s $(98.98 \pm 3.104 \%$ and $96.74 \pm 3.08 \%$, respectively). A second postsynaptic depolarization of a longer duration $(-70$ to $0 \mathrm{mV}$ for $10 \mathrm{~s})$ induced clear DSE in both female mice $(20.64 \pm 2.24 \%$ from baseline; one-way ANOVA, $F_{(5,135)}=34.71$; Tukey's post hoc analysis, $p<0.0001$; Fig. $6 A, C$, top) and male mice $(17.79 \pm 2.15 \%$ from baseline; one-way ANOVA, $F_{(5,84)}=35.18$; Tukey's post hoc analysis, $p<0.0001$; Fig. $6 B, C$, bottom), which recovered within $\sim 1 \mathrm{~min}$ ( $99.25 \pm 2.66 \%$ and $99.18 \pm 2.47 \%$, respectively). Post hoc analysis revealed similar DSE in inflamed CA1 pyramidal neurons from female mice ( $p=0.96$; Fig. $6 C$, top) and male mice ( $p=0.99$; Fig. 6C, bottom) compared with controls. We also verified that the DSE was eCB mediated, as it was blocked in the presence of AM251(CB1 receptor antagonist; Fig. 6A,B). Thus, a possible involvement of $\mathrm{eCB}$ receptor changes on glutamatergic terminals was unlikely to have contributed to the increased presynaptic glutamatergic transmission observed after early-life LPS administration.

Reduced presynaptic $\mathrm{GAB}_{\mathrm{B}}$ receptor activity induced by early-life inflammation

We further explored a potential mechanism that would explain higher glutamate release and altered excitability in CA1 pyramidal neurons following early-life inflammation. Thus, we considered a role for $\mathrm{GABA}_{\mathrm{B}}$ receptors, which are known to negatively regulate release probability via a presynaptic localization on glutamatergic hippocampal boutons (Colmers and Pittman, 1989; Kulik et al., 2006; Guetg et al., 2009). Interestingly, previous studies reported that mRNA expression, immunoreactivity, and presynaptic and postsynaptic responses of $\mathrm{GABA}_{\mathrm{B}}$ receptors are decreased in hippocampus and cortex of patients with epilepsy (Princivalle et al., 2002; Teichgräber et al., 2009). To the best of our knowledge, the impact of the early-life inflammation on $\mathrm{GABA}_{\mathrm{B}}$-mediated responses has not been documented. On these bases, we next investigated whether these receptors are differentially activated in control and inflamed CA1 pyramidal neurons of adult female and male mice exposed early in life to LPS.

Figure $7 \mathrm{~A}$ summarizes the hypothesis we tested (i.e., that early-life LPS treatment reduces $\mathrm{GABA}_{\mathrm{B}}$ receptor activity on Shaffer collateral glutamatergic terminals). Figure $7 B$ shows representative traces of evoked EPSC responses to electrical stimulation of presynaptic SC fibers for control (Fig. $7 B$, Veh, black traces) and previously-inflamed (Fig. $7 B$, LPS, green/blue traces) CA1 pyramidal neurons from adult female (Fig. $7 B$, left) and male mice (Fig. $7 B$, right) before and after the application of baclofen $(5 \mu \mathrm{M}), \mathrm{GABA}_{\mathrm{B}}$ receptor agonist. In both females and males pretreated with Veh and LPS, the application of baclofen caused an increased PPR (Fig. 7C,D), consistent with its presynaptic inhibitory action. However, its effectiveness was different as a function of early-life treatment. When comparing the effects of baclofen treatment on presynaptic glutamate release, statistical analysis revealed a significantly increased PPR in CA1 pyramidal neurons of female mice (Veh: $21.24 \pm 2.9 \%$ increase over baseline; paired Student's $t$ test, $t_{(9)}=6.97, p<0.0001, n=10, N=4$; LPS: $6.29 \pm 1.8 \%$ increase over baseline; $t_{(10)}=3.27, p=0.008$, $n=11, N=5$; Fig. $7 C$ ) and male mice (Veh: $25.55 \pm 4.55 \%$ over baseline; $t_{(9)}=5.65, p=0.0003, n=10, N=4$; LPS: $8.41 \pm 2.08 \%$ over baseline; $t_{(9)}=3.90, p=0.003, n=10, N=5$; Fig. $7 D$ ). Notably, in offspring exposed to early-life LPS inflammation, the baclofen-mediated increased PPR was less pronounced in both sexes (females: unpaired Student's $t$ test, $t_{(19)}=4.3, p=0.0004$; males: $t_{(18)}=3.42, p=0.003$; Fig. $7 C, D$, right) compared with control. Further, the percentage of the baclofen-induced decrease in eEPSC amplitude and the baclofen-induced increase in PPR in control and inflamed CA1 pyramidal neurons of female mice (Veh: $r=0.776, p=0.008$; LPS: $r=0.653, p=0.029$; Fig. $7 E$ ) and male mice (Veh: $r=0.779, p=0.008$; LPS: $r=0.641, p=0.045$; Fig. $7 F$ ) were found to be significantly and positively correlated.

$\mathrm{GABA}_{\mathrm{B}}$ receptor activity has been observed to modulate EPSC frequency, but not amplitude, at hippocampal glutamatergic synapses (Scanziani et al., 1992). Next, we explored whether spontaneous EPSC amplitude and frequency were also differentially affected by baclofen treatment in control and inflamed CA1 pyramidal neurons from adult animals. With this aim, spontaneous EPSCs were examined before and after the application of the $\mathrm{GABA}_{\mathrm{B}}$ agonist. Figure 8 shows spontaneous EPSCs for representative control (Veh, black traces) and early LPS-inflamed (LPS, green/blue traces) CA1 pyramidal neurons from both adult female (Fig. 8A) and male (Fig. 8B) mice. When comparing the effects of baclofen treatment on spontaneous EPSC amplitude, as expected, there were no significant effects in CA1 pyramidal neurons of females (Veh: 
A
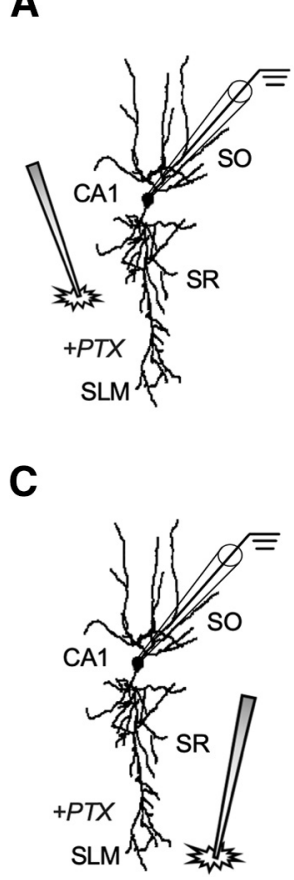

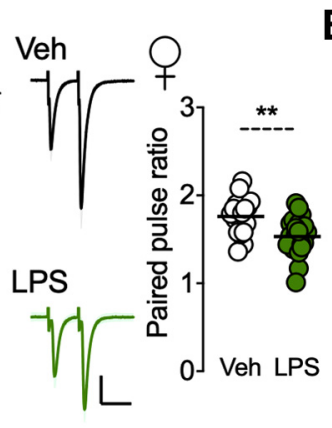

B
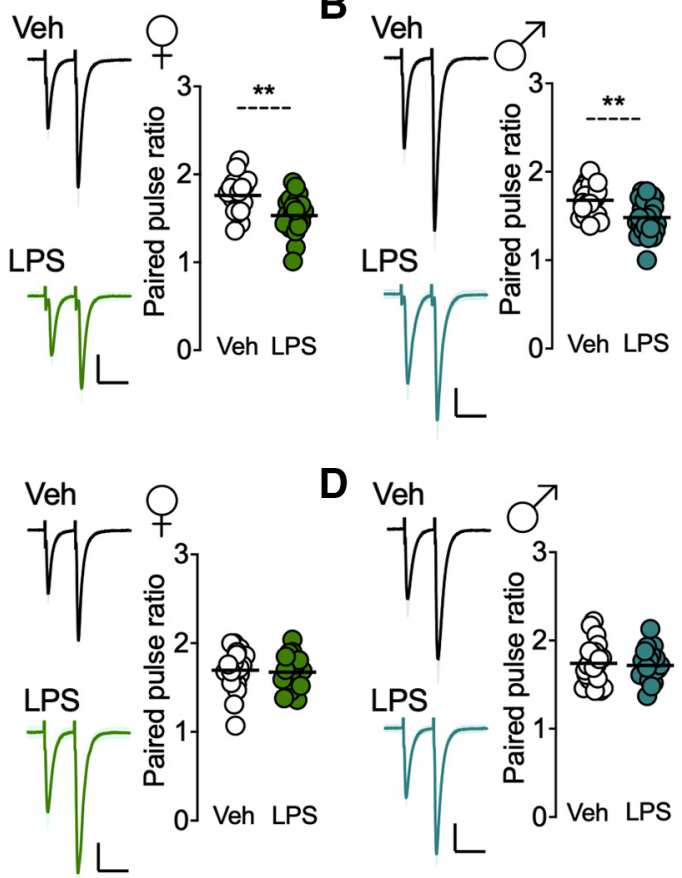

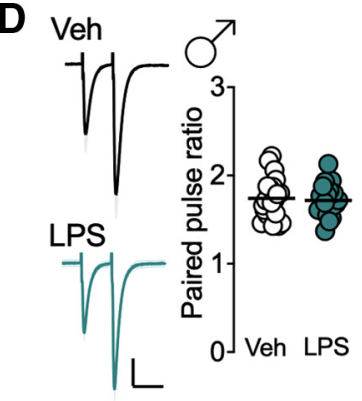

Figure 4. Early-life inflammation selectively increased the probability of glutamate release in adult mice. $\mathbf{A}-\mathbf{D}$, Representative scaled traces of paired pulse recording of CA1 pyramidal cells evoked by the stimulation of afferent fibers in the Schaffer collateral $(\boldsymbol{A}, \boldsymbol{B})$ or temporoammonic $(\boldsymbol{C}, \boldsymbol{D})$ pathway (as indicated on the schematic on the left) from adult female $(\boldsymbol{A}, \boldsymbol{C})$ and male $(\boldsymbol{B}, \boldsymbol{D})$ mice exposed early in life to Veh (dark traces) or LPS (green/blue traces) at P14. Calibration: $100 \mathrm{pA}, 50 \mathrm{~ms}$. Scatter graphs on right show PPR of individual cells. Summary data display decreased PPR in CA1 pyramidal cells from both female (green symbols) and male (blue symbols) mice exposed to early inflammation compared with controls (white symbols) when the Schaffer collateral $(\boldsymbol{A}, \boldsymbol{B})$ was stimulated. However, when the temporoammonic pathway was stimulated $(\boldsymbol{C}, \boldsymbol{D})$, no significant differences in PPR were observed. Horizontal lines are the mean $(n=18-25$ cells, 58 mice/group). SO, Stratum oriens; PTX, picrotoxin. $* * p<0.01$.

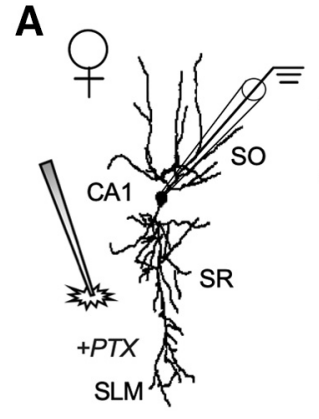

B

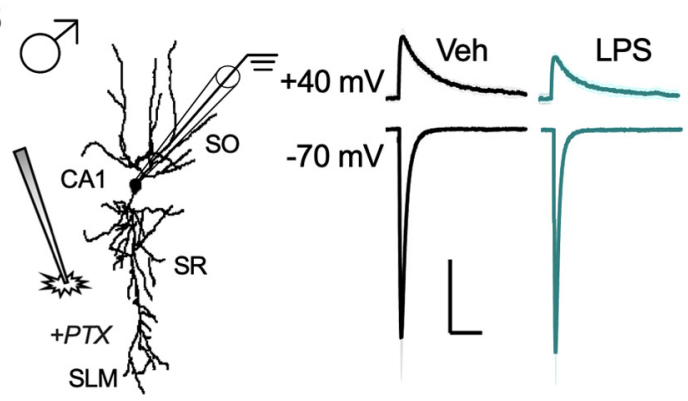

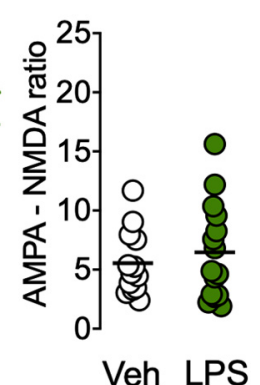

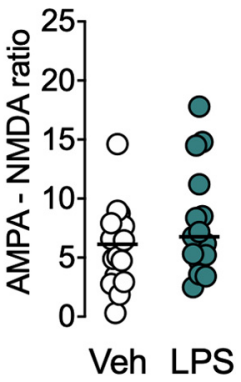

Figure 5. AMPA/NMDA ratio was not affected by early inflammation induced by LPS. $A, B$, Sample scaled traces of AMPA currents recorded at $-70 \mathrm{mV}$ and NMDA currents at $+40 \mathrm{mV}$ of CA1 pyramidal cells evoked by stimulation of afferent fibers in the Schaffer collateral pathway (as indicated on schematic on left) from adult female $(\boldsymbol{A})$ and male $(\boldsymbol{B})$ mice early exposed to Veh (dark traces) or LPS (green/blue traces) at P14. Calibration: 100 pA, 50 ms. Scatter graphs on right show the AMPA/NMDA ratio of individual cells. Summary data display no significant differences in the AMPA/NMDA ratio in pyramidal neurons from both female (green symbols) and male (blue symbols) mice early exposed to inflammation compared with controls (white symbols). Horizontal lines are the mean ( $n=13-19$ cells, 7-8 mice/group). SO, Stratum oriens; PTX, picrotoxin.

$-2.44 \pm 2.06 \%$ of baseline; paired Student'st test, $t_{(9)}=1.45, p=0.18 ;$ LPS: $-3.48 \pm$ $1.74 \%$ of baseline; $t_{(10)}=2.11, p=0.06$; Fig. $8 C$ ) and males (Veh" $-4.09 \pm 2.97 \%$ of baseline; $t_{(9)}=1.42, p=0.18$; LPS: $-4.40 \pm 3.05 \%$ of baseline; $t_{(9)}=1.50, p=0.16$; Fig. $8 D$ ). Furthermore, statistical analysis showed a significant decrease because of baclofen in EPSC frequency onto CA1 pyramidal neurons of female mice (Veh: $-55.19 \pm 9.8 \%$ from baseline; paired Student's $t$ test, $t_{(9)}=4.9$, $p=0.0008$; LPS: $-11.69 \pm 3.11 \%$ from baseline; $t_{(10)}=3.25, p=0.008$; Fig. $8 E$ ) and male mice (Veh: $-45.88 \pm 8.23 \%$ from baseline; $t_{(9)}=5.02, p=0.0007$; LPS: $-8.87 \pm 2.54 \%$ from baseline; $t_{(9)}=3.80, p=0.004$; Fig. $8 F$ ). However, in offspring exposed to early-life LPS inflammation, the baclofen-mediated decreased EPSC frequency was much less pronounced in both sexes (females: unpaired Student's $t$ test, $t_{(19)}=4.38, p=0.0003$; males: $t_{(18)}=4.30, p=0.0004$; Fig. $8 E, F$, right) compared with control. $G_{A B A}$ receptors are also located on postsynaptic pyramidal cells, where they are coupled by a different mechanism to potassium conductances (Colmers and Pittman, 1989). Nevertheless, statistical analysis shows no significant effect on resting membrane potential among groups in female mice (Veh: $-65.2 \pm 1.18 \mathrm{mV}$; plus baclofen, -64.7 $\pm 1.15 \mathrm{mV}$; paired Student's $t$ test, $t_{(9)}=0.97$, $p=0.35, n=10, N=4$; LPS: $-64.5 \pm 1.07 \mathrm{mV}$; plus baclofen, $-64.1 \pm 1.25 \mathrm{mV} ; t_{(10)}=0.42$, $p=0.68, n=11, N=5$ ) and male mice (Veh: $-65.0 \pm 1.64 \mathrm{mV}$; plus baclofen, $-64.5 \pm$ $1.02 \mathrm{mV} ; t_{(9)}=0.40, p=0.70, n=10, N=4$; LPS: $-64.7 \pm 0.97 \mathrm{mV}$; plus baclofen, $-63.8 \pm$ $\left.1.05 \mathrm{mV} ; t_{(9)}=1.21, p=0.26, n=10, N=5\right)$. Together, these data suggest that the mechanisms underlying the alterations in presynaptic glutamate release and seizure susceptibility may involve a reduced activity of presynaptic $\mathrm{GABA}_{\mathrm{B}}$ receptors on the glutamatergic terminals in the hippocampus.

\section{Discussion}

Our study provides novel evidence that early-life inflammation evoked by LPS during a critical period of development, by itself, causes an age-dependent but not sexdependent increased seizure susceptibility to the proconvulsant agent $\mathrm{PTZ}$ in vivo, which is associated with altered hippocampal synaptic transmission in vitro. These synaptic changes included increases in spontaneous EPSC frequency in CA1 pyramidal neurons, a selective increase of glutamate release from the Schaffer collateral, but not TA fibers and a decreased activity of presynaptic $\mathrm{GABA}_{\mathrm{B}}$ receptors, alterations that may underlie increased seizure susceptibility seen in response to PTZ injections. Another 
remarkable finding here is that all these changes were observed only in adult animals, and not in adolescent animals of either sex. Together, these observations demonstrate that a systemic early-life episode of inflammation caused CA1 pyramidal neurons of adult female and male mice to be synaptically more excitable than those of controls. This could be a contributing factor to altered network excitability during development and raises the possibility that such changes may underlie the seizure susceptibility, as well as some of the behavioral changes seen in adult animals after early-life inflammation.

The blood-brain barrier (BBB) normally protects the CNS against many systemic neurotoxic substances. It is well known that inflammation causes breakdown of the BBB through the upregulation of inflammatory molecules (Varatharaj and Galea, 2017), and it has been described as a pathogenic hallmark of epileptic foci in animal models of acquired epilepsies (Ravizza et al., 2008; Vezzani et al., 2015). At this time, we do not know whether the increase in seizure susceptibility observed is associated with a change in PTZ permeability into the brain mediated by alterations in BBB integrity. In neonate mice, however, the BBB was shown to be resistant to disruption even with a dose of LPS three times higher $(300 \mu \mathrm{g} / \mathrm{kg}$, i.p.) than the one used here. Furthermore, rupture of the hippocampal BBB was only seen with a high dose of LPS ( $3 \mathrm{mg} / \mathrm{kg}$, i.p.; Banks et al., 2015). Therefore, it is unlikely that our dose of $100 \mu \mathrm{g} / \mathrm{kg}$, i.p., LPS used to induce early-life inflammation results in BBB disruption. Furthermore, the fact that increased excitability was also seen in vitro is consistent with a direct neuronal effect of PTZ, independent of possible BBB changes. Future experiments might also address whether the altered seizure susceptibility seen in the adult females occurs for other convulsants, as has been reported in males.

Previous studies have described short-term alterations in the hippocampal expression levels of the inflammatory cytokines interleukin- $1 \beta$ (IL- $1 \beta$ ) and tumor necrosis factor- $\alpha$ (TNF- $\alpha$ ), and microglial activation induced by systemic inflammation with LPS at P14 (Galic et al., 2008; Dinel et al., 2014). Furthermore, we were able to show that brain TNF- $\alpha$ was causal for the increased seizure susceptibility (Galic et al., 2008). It is possible that TNF- $\alpha$ is also responsible for the synaptic changes we have seen in this study, although we cannot discount the possibility that the many other CNS changes, including the elevated interleukin- $1 \beta$ levels we previously reported (Galic et al., 2008), could also be implicated.

Peripheral LPS injection has been reported to acutely alter $>2400$ genes in microglia alone (Sousa et al., 2018); furthermore, proinflammatory cytokines have been reported to acutely affect many different conductances and receptors (Lynch, 2002). It is beyond the scope of the current article to identify the precipitating factors in the neonate that account for the current electrophysiological alterations observed. Brain inflammation is well known to increase brain excitability (Vezzani et al., 2013). However, most evidence suggests that the inflammatory response arising from the early-life LPS treatment does not persist into
B

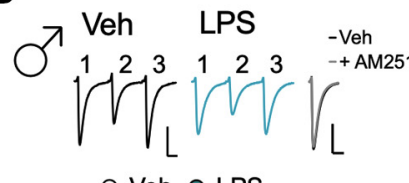

O Veh O LPS

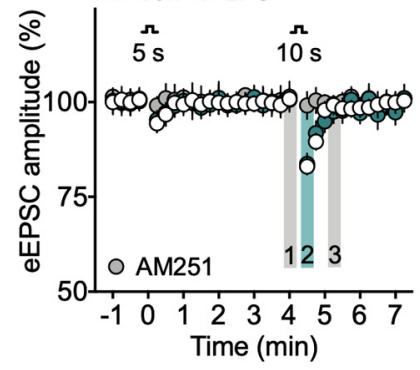

C

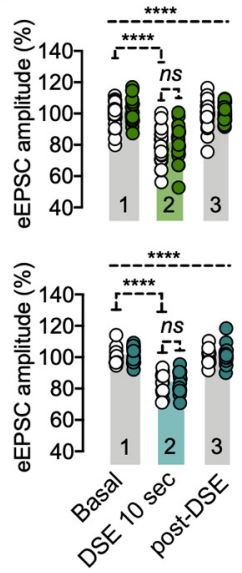

Figure 6. Early-life inflammation did not modify the DSE in adult CA1 pyramidal neurons. $\boldsymbol{A}, \boldsymbol{B}$, Representative traces of eEPSC recording (baseline: 1, immediately after 10 s postsynaptic depolarization: 2, and 1 min later: 3 , corresponding to the indicated shaded region below) of CA1 pyramidal cells evoked by stimulation in the Schaffer collaterals from adult female and male $(\boldsymbol{B})$ mice exposed in early life to Veh (dark traces) or LPS (green/blue traces) at P14. Far right superimposed (to between dificion different tom). $n=13-27$ cells, $5-6$ mice/group. $* * * * p<0.0001$, ns, not significant.

adulthood. Thus, it is unlikely that the effects we see in the current study arise from ongoing inflammatory activity. More likely, LPS effects induced transiently in the neonate (Galic et al., 2008; Dinel et al., 2014) may somehow become permanently entrenched when they occur in an early developmental stage.

Spontaneous EPSC frequency can be modulated through changes in the presynaptic function, comprising alterations in the number of synapses and/or in transmitter release (Kerchner and Nicoll, 2008; Acharjee et al., 2018). In line with this, there are dynamic changes in dendritic spine density induced by systemic inflammation (Bitzer-Quintero and González-Burgos, 2012). For example, a gradual increase over $4-8$ weeks of spine density was observed in cortices of mice exposed to LPS (Kondo et al., 2011). We did not observe any significant change between control and inflamed mice in spine density, number of bifurcated spines or spines with well defined heads located in the stratum lacunosum moleculare and stratum radiatum. Similar findings were obtained from P14 LPS-treated mice in another study, but the sex of the animals was not given (Shen et al., 2016). Thus, it is likely that other mechanisms may explain the observed effects of early-life LPS treatment on excitatory transmission in CA1 pyramidal cells. Our sEPSC data, and similar data from recordings of miniature EPSCs (Shen et al., 2016) revealing alterations in frequency, suggest a change in spontaneous glutamate release from excitatory terminals after early-life LPS treatment. Our evoked current data are even more definitive in this regard, showing a reduced PPR indicative of increased transmitter release in LPS-pretreated males and females. What was even more remarkable was that this was restricted to SR afferents and was not seen in SLM afferents. We are uncertain why there is this differential effect, but it should be noted that significant functional differences have been seen in response to stress and drug treatments in these two synaptic pathways (Kallarackal et al., 2013).

eCBs are one of the main systems controlling both excitatory and inhibitory neurotransmission, through activation of 
A

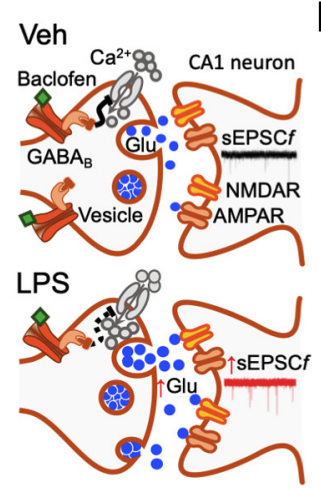

C

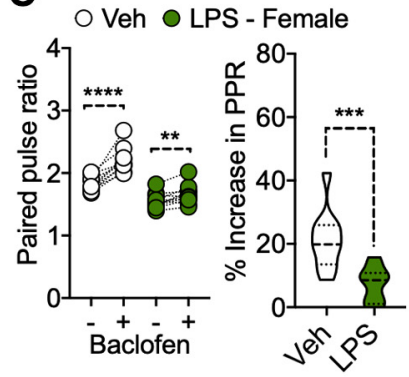

E

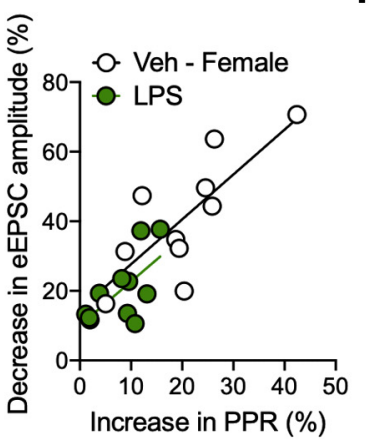

B

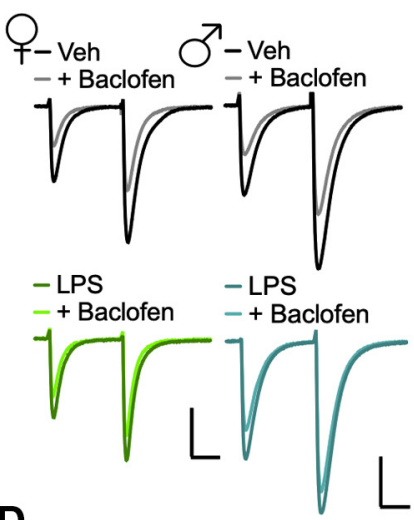

D

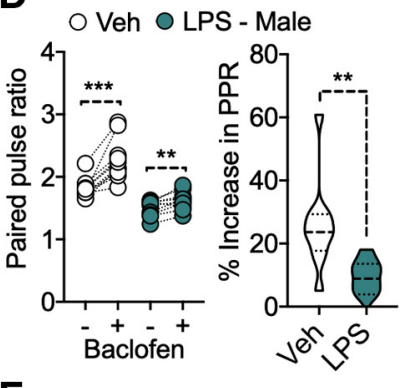

$F$

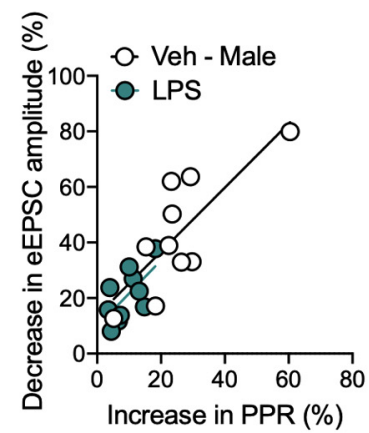

Figure 7. Early-life inflammation diminished presynaptic $G_{A B A_{B}}$ receptor activity in adult mice. $\boldsymbol{A}$, Top, Diagram showing synaptic cleft in presence of the $G_{B B A_{B}}$ receptor agonist baclofen in a vehicle-treated adult pyramidal cell; normal $G A B A_{B}$ receptor activity maintains low presynaptic glutamate release and low postsynaptic spontaneous EPSC frequency $(f)$. Bottom, Diagram illustrates that baclofen acting on $\mathrm{GABA}_{B}$ receptors is less effective (dotted line) to decrease presynaptic glutamate release and postsynaptic spontaneous EPSC $f$ in adult neonatally inflamed pyramidal cells. $\boldsymbol{B}$, Representative scaled traces of paired pulse recording (with/without baclofen) of CA1 pyramidal cells evoked by stimulation of afferent fibers in the Schaffer collateral pathway from adult female (left) and male (right) mice exposed in early life to Veh (dark traces) or LPS (green/blue traces). Calibration: 200 pA, 20 ms. C, D, Scatter graphs on left show PPR of individual cells (with/without baclofen) and violin graphs on right show the comparison of the percentage of change among groups in females $(\boldsymbol{C})$ and males $(\boldsymbol{D}) . \boldsymbol{E}, \boldsymbol{F}$, Pearson correlation coefficients between the baclofen-induced decrease in eEPSC amplitude and baclofen-induced increase in PPR from control and inflamed CA1 pyramidal neurons of female $(\boldsymbol{E})$ and male mice $(\boldsymbol{F}) . n=10-11$ cells, 4-5 mice/group. $* * p<0.01, * * * p<0.001, * * * * p<0.0001$.

presynaptic cannabinoid type 1 receptors (CB1Rs; Kreitzer and Regehr, 2001; Ohno-Shosaku et al., 2001; Wilson and Nicoll, 2001). These receptors are highly expressed in the hippocampus (Matsuda et al., 1993; Tsou et al., 1998). CB1R activation by its endogenous ligands anandamide (Devane et al., 1992) and 2arachidonylglycerol (Mechoulam et al., 1995; Sugiura et al., 1995) leads to several effects, including a decreased probability of glutamate release (Di Marzo et al., 1998). Previous studies show that prenatal or postnatal LPS treatment caused alterations in $\mathrm{CB} 1$ receptor binding and/or expression, in endocannabinoid

A

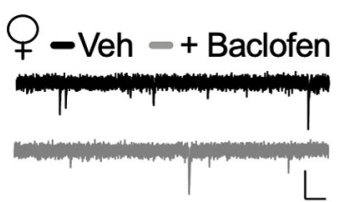

B

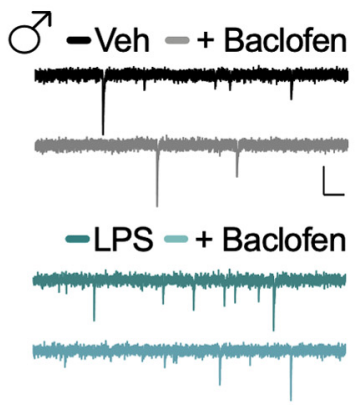

C

- LPS - + Baclofen

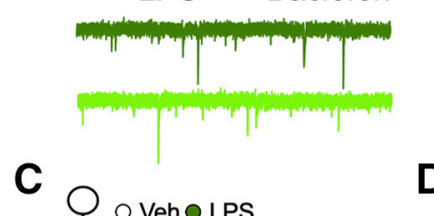

D $\bigcirc$ VeholPs
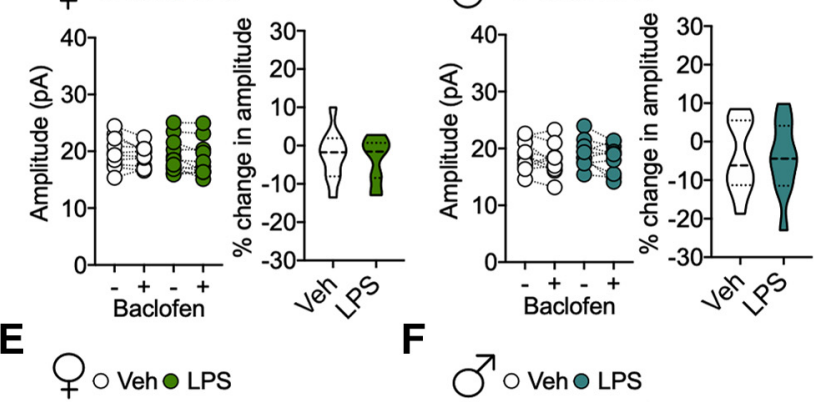

$\mathbf{F}$
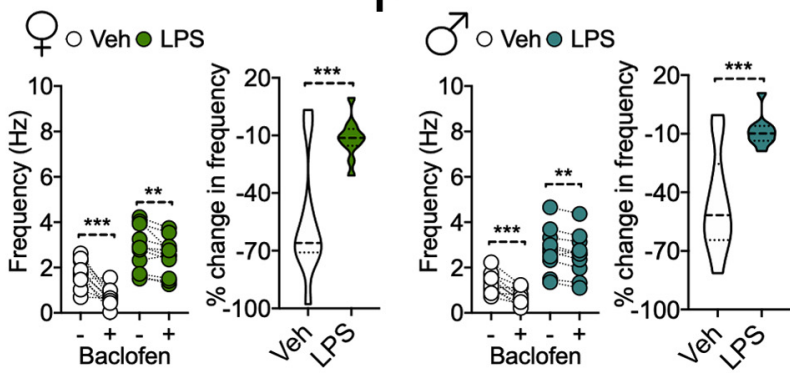

Figure 8. Early-life inflammation augmented spontaneous synaptic currents by decreasing presynaptic $G A B A_{B}$ receptor activity in adult mice. $\boldsymbol{A}, \boldsymbol{B}$, Representative traces of spontaneous EPSCS (with/without baclofen) of CA1 pyramidal neurons from adult female $(\boldsymbol{A})$ and male $(\boldsymbol{B})$ mice previously injected with Veh (dark traces) or LPS (green/blue traces) at P14 (top trace and after addition of baclofen). Calibration: 20 pA, 200 ms. C-F, Scatter graphs on left show amplitude and frequency for individual cells (with/without baclofen) and violin graphs on right show comparison of the percentages of change among groups in females $(\boldsymbol{C}, \boldsymbol{E})$ and males $(\boldsymbol{D}, \boldsymbol{F}) . n=10-11$ cells, 4-5 mice/group. $* * p<0.01$, $* * * p<0.001$.

levels, and in endocannabinoid-related plasticity of inhibitory synapses later in life (Zavitsanou et al., 2013; Doenni et al., 2016; Guo et al., 2018). Furthermore, a transient hyperthermic seizure in neonatal rats was shown to increase brain excitability (Dube et al., 2000) and alter short-term plasticity of IPSCs in adulthood in a cannabinoid-sensitive fashion (Chen et al., 2003; Feng et al., 2016). Nevertheless, our results revealed that early-life inflammation did not alter the endocannabinoid-related short-term plasticity of excitatory synapses in adult hippocampus. Thus, these findings suggest that early-life inflammation may not have longlasting impact on components of the eCB system controlling excitatory glutamate release in the SR-CA1 synapse of the hippocampus. This of course does not rule out possible alterations in the eCB system at other synapses both in the hippocampus and elsewhere in the brain.

It has been shown that presynaptic $\mathrm{GABA}_{\mathrm{B}}$ receptors are activated under basal synaptic activity and impact the probability of excitatory neurotransmitter release (Laviv et al., 2010). Activity changes in these receptors could influence neuronal excitability. For instance, $\mathrm{GABA}_{\mathrm{B}}$ receptor knock-out mice exhibited spontaneous seizures and developed a generalized epilepsy (Prosser et al., 2001; Schuler et al., 2001). In addition, $\mathrm{GABA}_{\mathrm{B}}$ receptor 
antagonists were shown to induce hippocampal seizure activity (Vergnes et al., 1997; Leung et al., 2005, 2019). Interestingly, a recent study shows that an early-life insult induced by kainic acid has a long-lasting effect in decreasing $\mathrm{GABA}_{\mathrm{B}}$ receptormediated presynaptic inhibition of glutamatergic terminals in the hippocampus (Leung, 2019). In line with this, we found that early-life LPS inflammation causes a reduced $\mathrm{GABA}_{\mathrm{B}}$ receptor activity in adult CA1 pyramidal neurons, thus increasing presynaptic glutamate release, which may ultimately lead to increased seizure vulnerability. However, future studies should focus on further clarifying the exact mechanisms by which early-life inflammation/stress insults affect $\mathrm{GABA}_{\mathrm{B}}$ activation and downstream pathways.

In conclusion, this study demonstrates that early-life inflammation leads to a selective increase of glutamate release from SC fibers and altered activity of $\mathrm{GABA}_{\mathrm{B}}$ receptors, resulting in augmented excitatory synaptic transmission in CA1 pyramidal cells from both female and male mice in adult life. Given that previously we have also seen changes in intrinsic membrane properties in male animals, one might predict that males would be particularly susceptible to early-life inflammation. Additionally, our results imply that changes in the hippocampal glutamatergic synaptic activity may play a crucial role in determining the increased seizure susceptibility that emerges in adulthood after early-life inflammatory challenges.

\section{References}

Aboubakr A, Chait J, Lurie J, Schanzer HR, Marin ML, Faries PL, Ting W (2019) Secondary interventions after iliac vein stenting for chronic proximal venous outflow obstruction. J Vasc Surg Venous Lymphat Disord 7:670-676.

Acharjee S, Verbeek M, Gomez CD, Bisht K, Lee B, Benoit L, Sharkey KA, Benediktsson A, Tremblay ME, Pittman QJ (2018) Reduced microglial activity and enhanced glutamate transmission in the basolateral amygdala in early CNS autoimmunity. J Neurosci 38:9019-9033.

Aksoy-Aksel A, Manahan-Vaughan D (2013) The temporoammonic input to the hippocampal CA1 region displays distinctly different synaptic plasticity compared to the Schaffer collateral input in vivo: significance for synaptic information processing. Front Synaptic Neurosci 5:5.

Auvin S, Shin D, Mazarati A, Sankar R (2010) Inflammation induced by LPS enhances epileptogenesis in immature rat and may be partially reversed by IL1RA. Epilepsia 51:34-38.

Banks WA, Gray AM, Erickson MA, Salameh TS, Damodarasamy M, Sheibani N, Meabon JS, Wing EE, Morofuji Y, Cook DG, Reed MJ (2015) Lipopolysaccharide-induced blood-brain barrier disruption: roles of cyclooxygenase, oxidative stress, neuroinflammation, and elements of the neurovascular unit. J Neuroinflammation 12:223.

Barker-Haliski M, White HS (2015) Glutamatergic mechanisms associated with seizures and epilepsy. Cold Spring Harb Perspect Med 5:a022863.

Ben-Ari Y, Khalilov I, Kahle KT, Cherubini E (2012) The GABA excitatory/ inhibitory shift in brain maturation and neurological disorders. Neuroscientist 18:467-486.

Berkiks I, Mesfioui A, Ouichou A, Nakache R, Ajonijebu DC, El Hessni A (2019a) Affective behavior shows sex differences in mid-adulthood rats following postnatal immune stimulation. Neuroscience 421:69-81.

Berkiks I, Garcia-Segura LM, Nassiri A, Mesfioui A, Ouichou A, Boulbaroud S, Bahbiti Y, Lopez-Rodriguez AB, Hasnaoui E, El Hessni A (2019b) The sex differences of the behavior response to early life immune stimulation: microglia and astrocytes involvement. Physiol Behav 199:386-394.

Bilbo SD, Biedenkapp JC, Der-Avakian A, Watkins LR, Rudy JW, Maier SF (2005) Neonatal infection-induced memory impairment after lipopolysaccharide in adulthood is prevented via caspase-1 inhibition. J Neurosci 25:8000-8009.

Bitzer-Quintero OK, González-Burgos I (2012) Immune system in the brain: a modulatory role on dendritic spine morphophysiology? Neural Plast 2012:348642.

Chen K, Ratzliff A, Hilgenberg L, Gulyás A, Freund TF, Smith M, Dinh TP, Piomelli D, Mackie K, Soltesz I (2003) Long-term plasticity of endocannabinoid signaling induced by developmental febrile seizures. Neuron 39:599-611.

Colmers WF, Pittman QJ (1989) Presynaptic inhibition by neuropeptide Y and baclofen in hippocampus: insensitivity to pertussis toxin treatment. Brain Res 498:99-104.

Danese A, Lewis SJ (2017) Psychoneuroimmunology of early-life stress: the hidden wounds of childhood trauma? Neuropsychopharmacology 42:99114.

Devane WA, Hanus L, Breuer A, Pertwee RG, Stevenson LA, Griffin G, Gibson D, Mandelbaum A, Etinger A, Mechoulam R (1992) Isolation and structure of a brain constituent that binds to the cannabinoid receptor. Science 258:1946-1949.

Di Marzo V, Melck D, Bisogno T, De Petrocellis L (1998) Endocannabinoids: endogenous cannabinoid receptor ligands with neuromodulatory action. Trends Neurosci 21:521-528.

Dinel A-L, Joffre C, Trifilieff P, Aubert A, Foury A, Le Ruyet P, Layé S (2014) Inflammation early in life is a vulnerability factor for emotional behavior at adolescence and for lipopolysaccharide-induced spatial memory and neurogenesis alteration at adulthood. J Neuroinflammation 11:155.

Doenni VM, Gray JM, Song CM, Patel S, Hill MN, Pittman QJ (2016) Deficient adolescent social behavior following early-life inflammation is ameliorated by augmentation of anandamide signaling. Brain Behav Immun 58:237-247.

Doenni VM, Song CM, Hill MN, Pittman QJ (2017) Early-life inflammation with LPS delays fear extinction in adult rodents. Brain Behav Immun 63:176-185.

Dube C, Chen K, Eghbal-Ahmadi M, Brunson K, Soltesz I, Baram TZ (2000) Prolonged febrile seizures in the immature rat model enhance hippocampal excitability long term. Ann Neurol 47:336-344.

Dupuis N, Mazarati A, Desnous B, Chhor V, Fleiss B, Le Charpentier T, Lebon S, Csaba Z, Gressens P, Dournaud P, Auvin S (2016) Pro-epileptogenic effects of viral-like inflammation in both mature and immature brains. J Neuroinflammation 13:307.

Dutta S, Sengupta P (2016) Men and mice: relating their ages. Life Sci 152:244-248.

Ellis S, Mouihate A, Pittman QJ (2005) Early life immune challenge alters innate immune responses to lipopolysaccharide: implications for host defense as adults. FASEB J 19:1519-1521.

Feng B, Tang Y, Chen B, Xu C, Wang Y, Dai Y, Wu D, Zhu J, Wang S, Zhou Y, Shi L, Hu W, Zhang X, Chen Z (2016) Transient increase of interleukin- $\beta$ after prolonged febrile seizures promotes adult epileptogenesis through long-lasting upregulating endocannabinoid signaling. Sci Rep 6:21931.

Galic MA, Riazi K, Heida JG, Mouihate A, Fournier NM, Spencer SJ, Kalynchuk LE, Teskey GC, Pittman QJ (2008) Postnatal inflammation increases seizure susceptibility in adult rats. J Neurosci 28:6904-6913.

Galic MA, Spencer SJ, Mouihate A, Pittman QJ (2009) Postnatal programming of the innate immune response. Integr Comp Biol 49:237-245.

Gomez CD, Read J, Acharjee S, Pittman QJ (2019) Early life inflammation increases CA1 pyramidal neuron excitability in a sex and age dependent manner through a chloride homeostasis disruption. J Neurosci 39:72447259.

Guetg N, Seddik R, Vigot R, Turecek R, Gassmann M, Vogt KE, BräunerOsborne H, Shigemoto R, Kretz O, Frotscher M, Kulik A, Bettler B (2009) The $\mathrm{GABA}_{\mathrm{B} 1 \mathrm{a}}$ isoform mediates heterosynaptic depression at hippocampal mossy fiber synapses. J Neurosci 29:1414-1423.

Guo Z, Tse YC, Zhang Y, Sun Q, Vecchiarelli HA, Aukema R, Hill MN, Wong TP, Boksa P (2018) Prenatal immune activation potentiates endocannabinoid-related plasticity of inhibitory synapses in the hippocampus of adolescent rat offspring. Eur Neuropsychopharmacol 28:1405-1417.

Hagberg H, Gressens P, Mallard C (2012) Inflammation during fetal and neonatal life: implications for neurologic and neuropsychiatric disease in children and adults. Ann Neurol 71:444-457.

Heida JG, Boissé L, Pittman QJ (2004) Lipopolysaccharide-induced febrile convulsions in the rat: short-term sequelae. Epilepsia 45:1317-1329.

Heida JG, Teskey GC, Pittman QJ (2005) Febrile convulsions induced by the combination of lipopolysaccharide and low-dose kainic acid enhance seizure susceptibility, not epileptogenesis, in rats. Epilepsia 46:1898-1905.

Kallarackal AJ, Kvarta MD, Cammarata E, Jaberi L, Cai X, Bailey AM, Thompson SM (2013) Chronic stress induces a selective decrease in AMPA receptor-mediated synaptic excitation at hippocampal temporoammonic-CA1 synapses. J Neurosci 33:15669-15674. 
Kentner AC, McLeod SA, Field EF, Pittman QJ (2010) Sex-dependent effects of neonatal inflammation on adult inflammatory markers and behavior. Endocrinology 151:2689-2699.

Kerchner GA, Nicoll RA (2008) Silent synapses and the emergence of a postsynaptic mechanism for LTP. Nat Rev Neurosci 9:813-825.

Kondo S, Kohsaka S, Okabe S (2011) Long-term changes of spine dynamics and microglia after transient peripheral immune response triggered by LPS in vivo. Mol Brain 4:27.

Kreitzer AC, Regehr WG (2001) Retrograde inhibition of presynaptic calcium influx by endogenous cannabinoids at excitatory synapses onto Purkinje cells. Neuron 29:717-727.

Kulik A, Vida I, Fukazawa Y, Guetg N, Kasugai Y, Marker CL, Rigato F, Bettler B, Wickman K, Frotscher M, Shigemoto R (2006) Compartmentdependent colocalization of Kir3.2-containing $\mathrm{K}^{+}$channels and $\mathrm{GABA}_{\mathrm{B}}$ receptors in hippocampal pyramidal cells. J Neurosci 26:4289-4297.

Laviv T, Riven I, Dolev I, Vertkin I, Balana B, Slesinger PA, Slutsky I (2010) Basal GABA regulates $\mathrm{GABA}_{\mathrm{B}} \mathrm{R}$ conformation and release probability at single hippocampal synapses. Neuron 67:253-267.

Lee SH, Han SH, Lee KW (2000) Kainic acid-induced seizures cause neuronal death in infant rats pretreated with lipopolysaccharide. Neuroreport 11:507-510.

Leung LS (2019) Long-lasting changes in hippocampal $\mathrm{GABA}_{\mathrm{B}}$-receptor mediated inhibition following early-life seizures in kindling-prone but not kindling-resistant rats. Brain Res Bull 150:231-239.

Leung LS, Canning KJ, Shen B (2005) Hippocampal afterdischarges after $\mathrm{GABA}_{\mathrm{B}}$-receptor blockade in the freely moving rat. Epilepsia 46:203-216.

Leung LS, Shen B, Huszka C (2019) Long-lasting disruption of spatial memory by $\mathrm{GABA}_{\mathrm{B}}$ receptor antagonist induced seizures. Epilepsy Behav 96:1-5.

Lewis ML, Kesler M, Candy SA, Rho JM, Pittman QJ (2018) Comorbid epilepsy in autism spectrum disorder: implications of postnatal inflammation for brain excitability. Epilepsia 59:1316-1326.

Lynch MA (2002) Interleukin-1 beta exerts a myriad of effects in the brain and in particular in the hippocampus: analysis of some of these actions. Vitam Horm 64:185-219.

Maejima T, Hashimoto K, Yoshida T, Aiba A, Kano M (2001) Presynaptic inhibition caused by retrograde signal from metabotropic glutamate to cannabinoid receptors. Neuron 31:463-475.

Matsuda LA, Bonner TI, Lolait SJ (1993) Localization of cannabinoid receptor mRNA in rat brain. J Comp Neurol 327:535-550.

Mechoulam R, Ben-Shabat S, Hanus L, Ligumsky M, Kaminski NE, Schatz AR, Gopher A, Almog S, Martin BR, Compton DR (1995) Identification of an endogenous 2-monoglyceride, present in canine gut, that binds to cannabinoid receptors. Biochem Pharmacol 50:83-90.

Missig G, Mokler EL, Robbins JO, Alexander AJ, McDougle CJ, Carlezon WA Jr (2018) Perinatal immune activation produces persistent sleep alterations and epileptiform activity in male mice. Neuropsychopharmacology 43:482-491.

Ohno-Shosaku T, Maejima T, Kano M (2001) Endogenous cannabinoids mediate retrograde signals from depolarized postsynaptic neurons to presynaptic terminals. Neuron 29:729-738.

Ohno-Shosaku T, Tsubokawa H, Mizushima I, Yoneda N, Zimmer A, Kano M (2002) Presynaptic cannabinoid sensitivity is a major determinant of depolarization-induced retrograde suppression at hippocampal synapses. J Neurosci 22:3864-3872.

Pittman QJ, Gómez CD, Read J, Lewis ML, Acharjee S (2019) Early life inflammation-it sticks to the brain. Curr Opin Behav Sci 28:136-141.

Princivalle AP, Duncan JS, Thom M, Bowery NG (2002) Studies of GABA receptors labelled with [(3)H]-CGP62349 in hippocampus resected from patients with temporal lobe epilepsy. Br J Pharmacol 136:1099-1106.

Prosser HM, Gill CH, Hirst WD, Grau E, Robbins M, Calver A, Soffin EM, Farmer CE, Lanneau C, Gray J, Schenck E, Warmerdam BS, Clapham C, Reavill C, Rogers DC, Stean T, Upton N, Humphreys K, Randall A, Geppert M, et al. (2001) Epileptogenesis and enhanced prepulse inhibition in $\mathrm{GABA}_{\mathrm{B} 1}$-deficient mice. Mol Cell Neurosci 17:1059-1070.

Rana SA, Aavani T, Pittman QJ (2012) Sex effects on neurodevelopmental outcomes of innate immune activation during prenatal and neonatal life. Horm Behav 62:228-236.

Ravizza T, Gagliardi B, Noé F, Boer K, Aronica E, Vezzani A (2008) Innate and adaptive immunity during epileptogenesis and spontaneous seizures: evidence from experimental models and human temporal lobe epilepsy. Neurobiol Dis 29:142-160.
Reid AY, Pittman QJ, Teskey GC (2012) A prolonged experimental febrile seizure results in motor map reorganization in adulthood. Neurobiol Dis 45:692-700.

Riazi K, Honar H, Homayoun H, Rashidi N, Dehghani M, Sadeghipour H, Gaskari SA, Dehpour AR (2004) Sex and estrus cycle differences in the modulatory effects of morphine on seizure susceptibility in mice. Epilepsia 45:1035-1042

Romijn HJ, Hofman MA, Gramsbergen A (1991) At what age is the developing cerebral cortex of the rat comparable to that of the full-term newborn human baby? Early Hum Dev 26:61-67.

Scanziani M, Capogna M, Gähwiler BH, Thompson SM (1992) Presynaptic inhibition of miniature excitatory synaptic currents by baclofen and adenosine in the hippocampus. Neuron 9:919-927.

Schmidt MV, Schmidt M, Enthoven L, van der Mark M, Levine S, de Kloet ER, Oitzl MS (2003) The postnatal development of the hypothalamic-pituitary-adrenal axis in the mouse. Int J Dev Neurosci 21:125-132.

Schuler V, Lüscher C, Blanchet C, Klix N, Sansig G, Klebs K, Schmutz M, Heid J, Gentry C, Urban L, Fox A, Spooren W, Jaton AL, Vigouret J, Pozza M, Kelly PH, Mosbacher J, Froestl W, Käslin E, Korn R, et al (2001) Epilepsy, hyperalgesia, impaired memory, and loss of pre- and postsynaptic $\mathrm{GABA}_{\mathrm{B}}$ responses in mice lacking $\mathrm{GABA}_{\mathrm{B}(1)}$. Neuron 31:47-58.

Semple BD, Dill LK, O’Brien TJ (2020) Immune challenges and seizures: how do early life insults influence epileptogenesis? Front Pharmacol 11:2.

Shen Y, Qin H, Chen J, Mou L, He Y, Yan Y, Zhou H, Lv Y, Chen Z, Wang J, Zhou YD (2016) Postnatal activation of TLR4 in astrocytes promotes excitatory synaptogenesis in hippocampal neurons. J Cell Biol 215:719734.

Sousa C, Golebiewska A, Poovathingal SK, Kaoma T, Pires-Afonso Y, Martina S, Coowar D, Azuaje F, Skupin A, Balling R, Biber K, Niclou SP, Michelucci A (2018) Single-cell transcriptomics reveals distinct inflammation-induced microglia signatures. EMBO Rep 19:e46171.

Spencer SJ, Boissé L, Mouihate A, Pittman QJ (2006) Long term alterations in neuroimmune responses of female rats after neonatal exposure to lipopolysaccharide. Brain Behav Immun 20:325-330.

Strange BA, Witter MP, Lein ES, Moser EI (2014) Functional organization of the hippocampal longitudinal axis. Nat Rev Neurosci 15:655-669.

Sugiura T, Kondo S, Sukagawa A, Nakane S, Shinoda A, Itoh K, Yamashita A, Waku K (1995) 2-Arachidonoylglycerol: a possible endogenous cannabinoid receptor ligand in brain. Biochem Biophys Res Commun 215:8997.

Teichgräber LA, Lehmann TN, Meencke HJ, Weiss T, Nitsch R, Deisz RA (2009) Impaired function of $\mathrm{GABA}_{B}$ receptors in tissues from pharmacoresistant epilepsy patients. Epilepsia 50:1697-1716.

Tsou K, Brown S, Sañudo-Peña MC, Mackie K, Walker JM (1998) Immunohistochemical distribution of cannabinoid CB1 receptors in the rat central nervous system. Neuroscience 83:393-411.

Varatharaj A, Galea I (2017) The blood-brain barrier in systemic inflammation. Brain Behav Immun 60:1-12.

Vergnes M, Boehrer A, Simler S, Bernasconi R, Marescaux C (1997) Opposite effects of GABAB receptor antagonists on absences and convulsive seizures. Eur J Pharmacol 332:245-255.

Vezzani A, Aronica E, Mazarati A, Pittman QJ (2013) Epilepsy and brain inflammation. Exp Neurol 244:11-21.

Vezzani A, Lang B, Aronica E (2015) Immunity and inflammation in epilepsy. Cold Spring Harb Perspect Med 6:a022699.

Walker AK, Nakamura T, Byrne RJ, Naicker S, Tynan RJ, Hunter M, Hodgson DM (2009) Neonatal lipopolysaccharide and adult stress exposure predisposes rats to anxiety-like behaviour and blunted corticosterone responses: implications for the double-hit hypothesis. Psychoneuroendocrinology 34:1515-1525.

Wilson RI, Nicoll RA (2001) Endogenous cannabinoids mediate retrograde signalling at hippocampal synapses. Nature 410:588-592.

Zavitsanou K, Dalton VS, Walker AK, Weickert CS, Sominsky L, Hodgson DM (2013) Neonatal lipopolysaccharide treatment has long-term effects on monoaminergic and cannabinoid receptors in the rat. Synapse 67:290-299.

Zucker RS, Regehr WG (2002) Short-term synaptic plasticity. Annu Rev Physiol 64:355-405. 